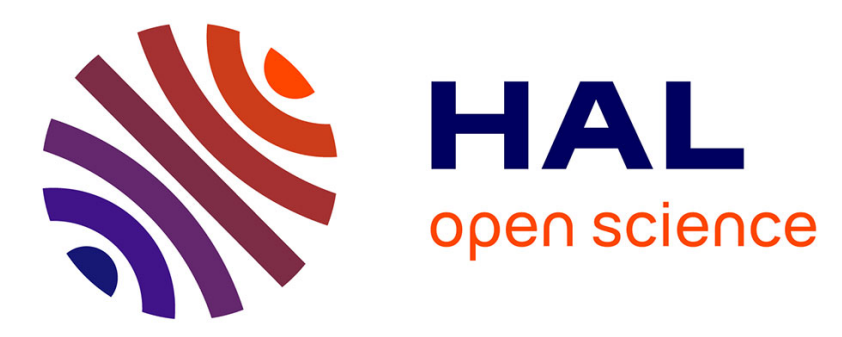

\title{
Variability of composition and effects of essential oils from Rhanterium adpressum Coss. \& Durieu against mycotoxinogenic Fusarium strains
}

Fatiha Elhouiti, Djilali Tahri, Djalila Takhi, Mohamed Ouinten, Christian Barreau, Marie-Noëlle Verdal-Bonnin, Isabelle Bombarda, Mohamed Yousfi

\section{To cite this version:}

Fatiha Elhouiti, Djilali Tahri, Djalila Takhi, Mohamed Ouinten, Christian Barreau, et al.. Variability of composition and effects of essential oils from Rhanterium adpressum Coss. \& Durieu against mycotoxinogenic Fusarium strains. Archives of Microbiology, 2017, 199 (10), pp.1345 - 1356. 10.1007/s00203-017-1404-z . hal-01777676

\section{HAL Id: hal-01777676 https://hal.science/hal-01777676}

Submitted on 25 Apr 2018

HAL is a multi-disciplinary open access archive for the deposit and dissemination of scientific research documents, whether they are published or not. The documents may come from teaching and research institutions in France or abroad, or from public or private research centers.
L'archive ouverte pluridisciplinaire HAL, est destinée au dépôt et à la diffusion de documents scientifiques de niveau recherche, publiés ou non, émanant des établissements d'enseignement et de recherche français ou étrangers, des laboratoires publics ou privés. 


\title{
Variability of composition and effects of essential oils from Rhanterium adpressum Coss. \& Durieu against mycotoxinogenic Fusarium strains
}

\author{
Fatiha Elhouiti ${ }^{1,2} \cdot$ Djilali Tahri $^{1} \cdot$ Djalila Takhi $^{3} \cdot$ Mohamed Ouinten $^{1} \cdot$ Christian Barreau $^{4}$. \\ Marie-Noëlle Verdal-Bonnin ${ }^{4} \cdot$ Isabelle Bombarda $^{5} \cdot$ Mohamed Yousfi $^{1}$
}

\begin{abstract}
The antifungal potency of the essential oils of Rhanterium adpressum was evaluated against four mycotoxigenic strains of the genus Fusarium. The essential oils were obtained, separately, by hydro-distillation of the aerial parts of $R$. adpressum (leaves and flowers). The parts were collected during the period of bloom ( 3 months) for 3 years. The GC-MS analysis revealed thirty-six compounds for the essential oils, divided into four classes of chemical compounds, with variable percentages according to the month of extraction. The monoterpene hydrocarbons form the main class in these oils. On the other hand, the highest percentages of the oxygenated compounds are observed in the samples collected during the month of May. The direct contact method was used to evaluate the antifungal activity of the essential oils. The activity can be attributed to their relatively high composition of oxygenated monoterpenes.
\end{abstract}

Fatiha Elhouiti

f.elhouiti@lagh-univ.dz

1 Laboratoire de Recherche des Sciences Fondamentales, Université Amar TELIDJI, Route de Ghardaïa, BP 37G, 03000 Laghouat, Algeria

2 Laboratoire de Recherche Valorisation et Promotion des Ressources Sahariennes (LVPRS), Université de Ouargla, Route de Ghardaïa, BP 511, 30000 Ouargla, Algeria

3 Laboratoire de Recherche Exploration et Valorisation des Écosystèmes Steppiques, Université Ziane Achour, BP 3117 , 17000 Djelfa, Algeria

4 Institut National de la Recherche Agronomique, INRA, UR1264, MycSA, BP 81, 71 Avenue Edouard Bourleaux, Villenave d'Ornon Cedex, 33883 Bordeaux, France

5 Laboratoire LISA, Équipe METICA, EA 4672, Université Aix-Marseille, Marseille, France
Flowers extract showed strong inhibitory activity, with very interesting concentrations of IC50 and MIC for both tests on solid and liquid medium. The effect of these oils on the production of type B trichothecenes (TCTBs) was evaluated, showing a significant inhibitory effect on TCTBs production, for both extracts (leaves and flowers). The rates of inhibition were $66-97$ and $76-100 \%$ of FX, 3-ADON and $15-\mathrm{ADON}$, respectively. The inhibition of fungal biomass and the production of TCTBs depended on the used concentration of the essential oils. These results suggest that the essential oils from $R$. adpressum are able to control the growth of the tested strains and their subsequent production of TCTB mycotoxins.

Keywords Essential oils - Rhanterium adpressum . Antifungal activity $\cdot$ Fusarium culmorum $\cdot$ Fusarium graminearum $\cdot$ Mycotoxin production

\section{Introduction}

Algeria offers an important and unexplored plant potential. In the studies of natural resources, several plant substances have been identified and have been proven to be useful for therapeutic purposes. In this context, the unexplored antifungal and antimycotoxigenic activities of the essential oils (EO) of Rhanterium adpressum Coss. \& Durieu, have been studied. This spontaneous Asteraceae, commonly called Aarfadj, is found in different areas in southern Algeria (Chehma 2006). It is often used by the local population for tanning and as an antidiuretic in folk medicine (Bouheroum et al. 2007).

Many diseases affecting plants are of fungal origin. Among these, and one of the most damaging, is "Ear Fusariosis". It is widespread in small-grain cereals such 
as wheat, barley, oats and corn. This disease causes severe symptoms on different parts of the affected plants and can provoke necrosis of the ears. Thus, it generates significant quality and yield losses, and may lead to the loss of all crops (Pirgozliev et al. 2003).

The main phytopathogenic agents responsible for this fusariosis are the ascomycete fungi belonging to the genera Fusarium and Microdochium, including Fusarium graminearum and Fusarium culmorum. During the infection, these phytopathogenic fungi, with mycotoxigenic potential, can produce two major families of mycotoxins: trichothecenes B (TCTBs) and zearalenone (ZEN) (Merhej et al. 2011).

There are few studies on secondary metabolites of Ranthterium species mentioned in scientific literature (Bouheroum et al. 2007; Hamia et al. 2013; Kala et al. 2009). Organic extracts (ethyl acetate) from Ranthterium adpressum flowers and aerial parts of Rhanterium suaveolens were found to offer a potential source of antioxidants (Boussoussa et al. 2014; Bouaziz et al. 2009). The essential oils extracted by hydro-distillation from the aerial parts of the plant showed antifungal activity against Fusarium oxysporum (El Houiti et al. 2016).

In this work, the inhibition of fungal biomass using essential oils extracted from $R$. adpressum, the kinetics of mycelial growth and the rate of inhibition in the presence of different concentrations of EOs were studied. In addition, the inhibition of TCTBs production by the EOs was examined. Eventually, this work will provide solutions for the preservation of food by proposing natural plant molecules that can serve as antifungal agents. These products could replace chemical fungicides that could be used to, partially or totally, inhibit the growth of fungi causing deleterious effects to economically important plant crops such as wheat, barley or corn.

The purpose of this work was to study the chemical composition of the essential oils (leaves and flowers) extracted from plant samples collected over 3 months, during 3 years. On the other hand, the antifungal and mycotoxigenic properties against four phytopathogenic and mycotoxinogenic isolates of the genus Fusarium (two $F$. graminearum and two $F$. culmorum) were assessed. The effects of the two EOs were evaluated on three major parameters:

- The kinetics of mycelial growth, in solid medium;

- The rate of inhibition of the mycelium, by two methods (by the method of direct contact, and in a liquid medium by, the microdilution technique);

- The inhibition of the production of mycotoxins type B trichothecenes by UPLC analysis, to quantify the accumulation of mycotoxins (3-ADON and 15-ADON and Fx).

\section{Materials and methods}

\section{Plant material and extraction of the essential oils}

The aerial parts of Rhanterium adpressum were collected on three different months (April, May and June), for 3 years: 2011, 2012 and 2013 by Pr Yousfi Mohamed. The identification of the plant was performed by Pr Chehma Abedelmajid, a botanist from Biology Department, University of Ouargla Algeria. The samplings took place at the area of Zelfana (Department of Ghardaia), located $660 \mathrm{~km}$ SSE of Algiers: latitude 32 $23^{\prime} 46^{\prime \prime}(\mathrm{N})$; longitude $5^{\circ} 13^{\prime} 34^{\prime \prime}(\mathrm{E})$; altitude $354 \mathrm{~m}$. A voucher specimen (RACD47/05/07) was deposited in the herbarium of the Fundamental Sciences Research Laboratory at Laghouat University (Hamia et al. 2013).

The freshly collected samples were dried at room temperature, away from light and humidity. The plant was then divided into two parts: the flowers and the stems. The essential oil was obtained by hydro-distillation during $6 \mathrm{~h}$, using a Clevenger type apparatus. The obtained oil was treated by anhydrous sodium sulfate, filtrated then stored at $+4{ }^{\circ} \mathrm{C}$, until analysis.

\section{Analysis of essential oils}

The separation of the compounds of the EO was performed by Agilent technologies 7890A gas chromatograph (GC), equipped with a flame ionization detector (FID), with a HP5 capillary column $(30 \mathrm{~m} \times 0.32 \mathrm{~mm}$, film thickness $0.40 \mu \mathrm{m}$ ). The oven temperatures program was as follows: $2 \mathrm{~min}$ at $80{ }^{\circ} \mathrm{C}$; from 80 to $200{ }^{\circ} \mathrm{C}$ at $5{ }^{\circ} \mathrm{C} / \mathrm{min} ; 5 \mathrm{~min}$ at $200{ }^{\circ} \mathrm{C}$; then from 200 to $260{ }^{\circ} \mathrm{C}$ at $20{ }^{\circ} \mathrm{C} / \mathrm{min}$; followed by $5 \mathrm{~min}$ at $260{ }^{\circ} \mathrm{C}$. Detector and inlet temperatures were $280{ }^{\circ} \mathrm{C}$. Hydrogen was used as a carrier gas at a constant flow of $1 \mathrm{~mL} / \mathrm{min}$ with a split ratio 70/1. The injections were $1 \mu \mathrm{L}$ of essential oil in methylene chloride (50 mg of EO in $1 \mathrm{~mL} \mathrm{CH}_{2} \mathrm{Cl}_{2}$ ).

The GC-MS analysis was performed using an Agilent technologies gas chromatography $7890 \mathrm{~A}$ equipped with a HP5MS capillary column $(30 \mathrm{~m} \times 0.25 \mathrm{~mm} \times 0.25 \mu \mathrm{m})$, and a mass detector MS 5975C VL MSD operated in EI mode. Helium was used as a carrier gas at a flow rate of $1 \mathrm{~mL} / \mathrm{min}$, split 50:1. The oven temperature program was as follows: $2 \mathrm{~min}$ at $80{ }^{\circ} \mathrm{C}$; from 80 to $200{ }^{\circ} \mathrm{C}$ at $5{ }^{\circ} \mathrm{C} /$ min; 5 min at $200{ }^{\circ} \mathrm{C}$; then from 200 to $260{ }^{\circ} \mathrm{C}$ at $20{ }^{\circ} \mathrm{C} /$ $\mathrm{min}$; followed by $5 \mathrm{~min}$ at $260^{\circ} \mathrm{C}$. Detector and inlet temperatures were $280{ }^{\circ} \mathrm{C}$. Identification of components was based on comparison of their mass spectra with those of WILEY and NIST Libraries, as well as on comparison of their retention indices with literature (Adams 2007; Benzo et al. 2007). 


\section{Fungal strains}

In this study, four mycotoxinogenic strains of the genus Fusarium were tested for antifungal activity. These strains are known to cause spoilage of cereals. Two isolates of $F$. graminearum from the INRA-MycSA laboratory (PH-1, NRRL 31084, originally isolated from Michigan) from chemotype DON/15-ADON coded INRA 812, and CBS 185.32 (Centraal Bureau voor Shimmelkulturen, Netherlands) from the chemotype DON/15-ADON coded INRA 349. Two isolates of $F$. culmorum were also tested. These isolates were collected in Oued Smar and Rouiba (North of Algeria), and belong to the Mycothèque Touati-Hattab $\mathrm{S}$. (one isolate of the chemotype NIV/FX coded T5; the other from the chemotype DON/3-ADON-coded BD17). All these strains have a high ability to produce Type B trichothecenes (TCTBs).

\section{Antifungal activity}

The EOs from June 2013 samples (leaves and flowers) were chosen for the tests of activity because they presented the highest yields. Various methods exist to access the antifungal activity of essential oils (Amvam Zollo et al. 1998). The effects of our EOs were evaluated regarding two major parameters:

- Kinetics of mycelial growth in solid medium.

- Rate of mycelium inhibition, which was evaluated by two methods: in solid medium by the method of direct contact, and in liquid medium by the microdilution technique using 96-well microplates.

To inoculate the solid and liquid culture media, a 5-mm diameter agar disk containing mycelium was transferred onto the center of PDA medium plates (Potato Dextrose Agar), using a pure culture prepared beforehand. Incubation was carried out at $25 \pm 2{ }^{\circ} \mathrm{C}$ for 6 days (Collin et al. 1989). Another liquid medium (CMC, Carboxymethyl cellulose) was used to promote the production of spores which serves as an inoculum for the synthetic liquid culture medium (LSM, liquid synthetic medium).

\section{Kinetics of fungal growth}

Different concentrations of the EOs, ranging from 0.5 to $20 \mu \mathrm{L} / \mathrm{mL}$, were added to the culture medium. Afterwards, the kinetics of the fungal growth was determined by measuring the diameter of the growth daily at the same hour.

\section{Antifungal activity on solid medium}

The effect of the EOs on mycelial development was evaluated using the direct contact method by calculating the inhibition percentage of the mycelium after 7 days of incubation at $25 \pm 2{ }^{\circ} \mathrm{C}$ (El Ajjouri et al. 2008; Remmal et al. 1993; Satrani et al. 2001).

$1 / 5$ th-1/200th dilutions of the EOs were prepared in an agar solution (2\%). In tubes, each containing $13.5 \mathrm{~mL}$ of sterile PDA medium $\left(45^{\circ} \mathrm{C}\right), 1.5 \mathrm{~mL}$ of each essential oil dilution was added to obtain final concentrations ranging from 0.5 to $20 \mu \mathrm{L} / \mathrm{mL}$. The tubes were then shacked and poured into Petri plates. Witnesses, containing the medium and agar solution without EO were prepared and used as controls. The Petri plates were inoculated by putting an agar disc containing mycelium taken from the periphery of the thallus derived from a Fusarium culture of 7 days on PDA. A Fusarium culture on PDA medium without extract was used as a control. The cultures were incubated in the dark at $25 \pm 2{ }^{\circ} \mathrm{C}$ for 7 days. The antifungal activity was determined by comparing the mycelial growth after treatment, with the mycelial growth of the control, then by calculating the percentage of mycelial inhibition.

\section{Antifungal activity on liquid culture medium}

The antifungal properties of the EOs were accessed by determining the rate of mycelium inhibition on liquid medium by the microdilution technique, using 96-well microplates. $10 \mu \mathrm{L}$ of inoculum with a concentration of $10^{6}$ spores $/ \mu \mathrm{L}$ of each fungal species were diluted in a liquid synthetic culture medium (LSM). After inoculation, the microtiter plates were treated with appropriate doses of the EOs to obtain concentrations ranging from 0.25 to $10 \mu \mathrm{L} / \mathrm{mL}$ per well (Fleurat-Lessard et al. 2015). Each strain is tested on the same microplate for different concentrations, hence the use of a transparent adhesive film to close the wells (avoid mixing due to volatility). Then, the whole is left to grow for 4 days, at $25^{\circ} \mathrm{C}$ in total darkness. A series of repetition are made, three wells (repetitions) for each concentration as well as for controls.

The assessment of mycelial growth is determined by comparing the fungal growth with and without EOs (controls). The antifungal activity was evaluated by measuring the absorbance at $630 \mathrm{~nm}$ immediately after the period of Incubation by a simple spectrophotometric reading (microplate reader Bio-TEK@instruments ELX 800, Germany).

The IC50 (50\% inhibitory concentrations) and MIC (minimal inhibitory concentrations) were determined for both extracts (leaves and flowers) against all tested strains. 


\section{Analysis of mycotoxin production for the treated fungi}

The same extracts (June 2013) were chosen for this analysis. The TCTBs were extracted from $4 \mathrm{~mL}$ of liquid culture medium, recovered after 4 days of incubation, and centrifuged to remove the mycelium, to which two volumes of ethyl acetate were added. After mixing in a vortex $(1 \mathrm{~min})$ and decantation, $2 \mathrm{~mL}$ of the supernatant were evaporated under a stream of nitrogen $\left(\right.$ at $\left.50{ }^{\circ} \mathrm{C}\right)$. The dry residue was recovered in $1 \mathrm{~mL}$ of methanol/water mixture $(50 / 50 \mathrm{v} / \mathrm{v})$. Subsequently, it was filtered through a $0.45 \mu \mathrm{m}$ porosity filter and analyzed by ultra performance liquid chromatography (UPLC), coupled to a detector with diode arrays (DAD).

The quantification of TCTB was performed on a Shimadzu Prominence UPLC chain, equipped with two pumps LC-20 AD, a degasser DGU-20A3R, an auto sampler SIL$30 \mathrm{AC}$ and a diode-array detector SPD-M20A (Shimadzu Scientific Instruments, France). Separation was achieved on a Kinetex 2,6U XB-C18 $100 \AA$ A column $(150 \times 4.6 \mathrm{~mm}$, $2.6 \mu \mathrm{m}$ ) (Phenomenex, France) maintained at $45{ }^{\circ} \mathrm{C}$. Mobile phase consisted of water acidified with ortho-phosphoric acid to reach $\mathrm{pH} 2.6$ (solvent A) and acetonitrile (solvent B). The following gradient was used for elution: $7 \%$ B for $1 \mathrm{~min}, 7-30 \%$ B for $6 \mathrm{~min}, 30-90 \%$ B for $2 \mathrm{~min}$, $90 \%$ B for $2 \mathrm{~min}, 90-7 \%$ B for $1 \mathrm{~min}$, and 6 min post-run equilibration with initial conditions. The flow was kept at $0.7 \mathrm{~mL}$ min- 1 for a total run time of $18 \mathrm{~min}$. The injection volume was $0.5 \mu \mathrm{L}$. The UV-Vis spectra were recorded from 220 to $550 \mathrm{~nm}$ and peak areas were measured at $230 \mathrm{~nm}$. Quantification was performed using external calibration ranging from 6.25 to $100 \mu \mathrm{g} / \mathrm{g}$ prepared with standard solutions (Romer Labs, Austria).

\section{Statistical analysis}

All experiences were performed in triplicate. Data processing was carried out with Origin b9.3.226. The significant differences between mean values were analyzed by an ANOVA oneway with significant values at $P<0.05$. The determination of IC50 and MIC was performed with dose-response curve with variable Hill slope at error probability $\leq 0.05$.

\section{Results and discussion}

\section{Variability of the chemical composition of essential oils}

The GC/MS analysis of the essential oils allowed the identification of 36 compounds, for both parts leaves and flowers (Fig. 1). These compounds are divided into four classes (Table 1), with varying percentages according to the month of plant collection. Mainly the temperature of the region (Holopainen et al. 2013), where the flowering period occurs between the months of April and May, could influence this variability. As of June, the temperature increases. Thus, the percentages of the classes are high in the samples collected in May, where the average temperatures are between 21 and $24{ }^{\circ} \mathrm{C}$. Monoterpene hydrocarbons form the main class of compounds in the extracts. As for the oxygenated compounds, their rates are at their maximum in the samples collected in May, especially in the flowers extract.

Compounds known as important antimicrobials (Bajpai et al. 2013; Dorman and Deans 2000) are present in the extracts with more or less high concentrations, such as: $\alpha$-Pinene (11.54\%: leaves, $15.64 \%$ : flowers), $\beta$-Myrcene (21.59\%: leaves, $12.81 \%$ : flowers), $\alpha$-Thujene $(0.33 \%$ : leaves, $0.22 \%$ : flowers), $\beta$-Pinene (13.91\%: leaves, $9.92 \%$ : flowers), $\delta$-Cadinene (1.16\%: leaves, $1.20 \%$ : flowers), Linalool (6.04\%: leaves, $6.07 \%$ : flowers), Geraniol (1.02\%: leaves, $1.19 \%$ : flowers), $\alpha$-Eudesmol (2.64\%: leaves, $3.01 \%$ : flowers) (Dorman and Deans 2000; Özek et al. 2008; Kim et al. 1995; Böhme et al. 2014). Antimicrobial activity is influenced even more by the high percentages of oxygenated compounds (Bajpai et al. 2013). Extracts from June showed a good antifungal activity, compared to the extracts of May and April, where the percentage of compounds is lower (Fig. 2).

\section{Kinetics of fungal growth}

The kinetics of the fungal growth of the selected strains (Fig. 3) in the presence of different concentrations of the EOs showed variable susceptibilities $(P \leq 0.05)$. The effect of leaves essential oil on mycelial growth is observed from a concentration of $2 \mu \mathrm{L} / \mathrm{mL}$. The strains INRA 349 and INRA 812 of Fusarium graminearum were less affected than the Fusarium culmorum strains.

A remarkable sensitivity of all strains to the EO of flowers was observed. Starting from the concentration of $1 \mu \mathrm{L} /$ $\mathrm{mL}$, the inhibition of growth was very important. As for leaves extract, the inhibition was at its maximum at the concentration of $10 \mu \mathrm{L} / \mathrm{mL}$, and a total inhibition was recorded at $20 \mu \mathrm{L} / \mathrm{mL}$. On the other hand, the extract of the flowers inhibited totally the growth of all strains at 10 and $20 \mu \mathrm{L} /$ $\mathrm{mL}$, while the concentration of $4 \mu \mathrm{L} / \mathrm{mL}$ induced a strong inhibition of mycelial growth.

The two strains of $F$. graminearum appeared to be much more sensitive to the flowers extract, particularly the INRA 812 strain, where the concentration of $4 \mu \mathrm{L} /$ $\mathrm{mL}$ showed a very similar effect to those obtained with 10 and $20 \mu \mathrm{L} / \mathrm{mL}$. Some of the results of Velluti et al. (2004), on the effect of essential oils of five plants on the growth of $F$. graminearum, showed a more or less significant effect at the concentration of $1 \mu \mathrm{L} / \mathrm{mL}$. Similarly, 

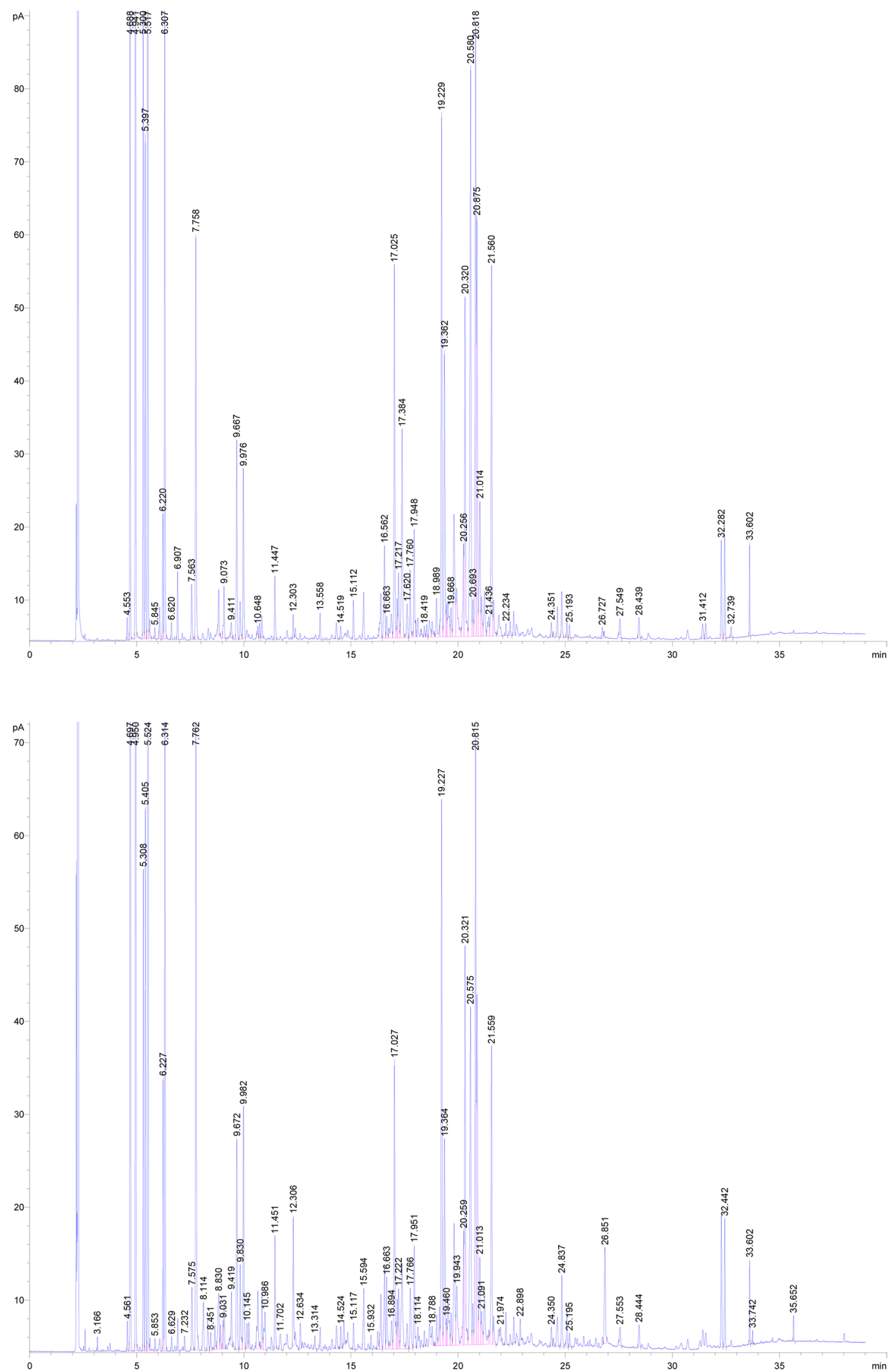

Fig. 1 Chromatogram of Rhanterium adpressum Coss. \& Durieu essential oil using a HP-5 capillary column (leaves, above and flowers, below) 
Table 1 The variation of the percentages of the chemical compounds classes according to the month of extraction for the two parts of the plant (leaves or flowers)

\begin{tabular}{lrrrrrrrr}
\hline & Ap 11 & Ma 11 & Ju 11 & Ap 12 & Ma 12 & Ju 12 & Ma 13 & Ju 13 \\
\hline Leaves & & & & & & & & \\
Monoterpene hydrocarbons & 54.49 & 63.77 & 67.17 & 57.77 & 69.71 & 64.21 & 44.35 & 22.50 \\
Oxygenated monoterpenes & 13.32 & 6.25 & 6.06 & 4.24 & 5.04 & 7.42 & 6.32 & 7.12 \\
Total monoterpenes & 67.80 & 70.01 & 73.23 & 62.01 & 74.75 & 71.63 & 50.67 & 29.62 \\
Sesquiterpene hydrocarbons & 3.70 & 4.10 & 2.61 & 7.29 & 5.14 & 1.58 & 5.50 & 5.30 \\
Oxygenated sesquiterpenes & 6.42 & 5.09 & 4.91 & 5.30 & 2.42 & 4.66 & 1.97 & 2.38 \\
Total sesquiterpenes & 10.12 & 9.20 & 7.52 & 12.58 & 7.56 & 6.24 & 7.47 & 7.68 \\
Flowers & & & & & & & & \\
Monoterpene hydrocarbons & 44.69 & 49.28 & 39.85 & 44.80 & 43.21 & 39.78 & 34.11 & 36.21 \\
Oxygenated monoterpenes & 10.82 & 10.20 & 11.74 & 4.05 & 8.36 & 12.64 & 10.12 & 7.66 \\
Total monoterpenes & 55.51 & 59.48 & 51.59 & 48.84 & 51.58 & 52.43 & 44.23 & 43.87 \\
Sesquiterpene hydrocarbons & 3.96 & 3.95 & 4.98 & 2.54 & 3.37 & 1.46 & 2.55 & 3.14 \\
Oxygenated sesquiterpenes & 7.06 & 6.53 & 8.57 & 6.30 & 7.93 & 6.01 & 2.93 & 1.64 \\
Total sesquiterpenes & 11.02 & 10.48 & 13.55 & 8.83 & 11.30 & 7.47 & 5.49 & 4.79 \\
\hline
\end{tabular}

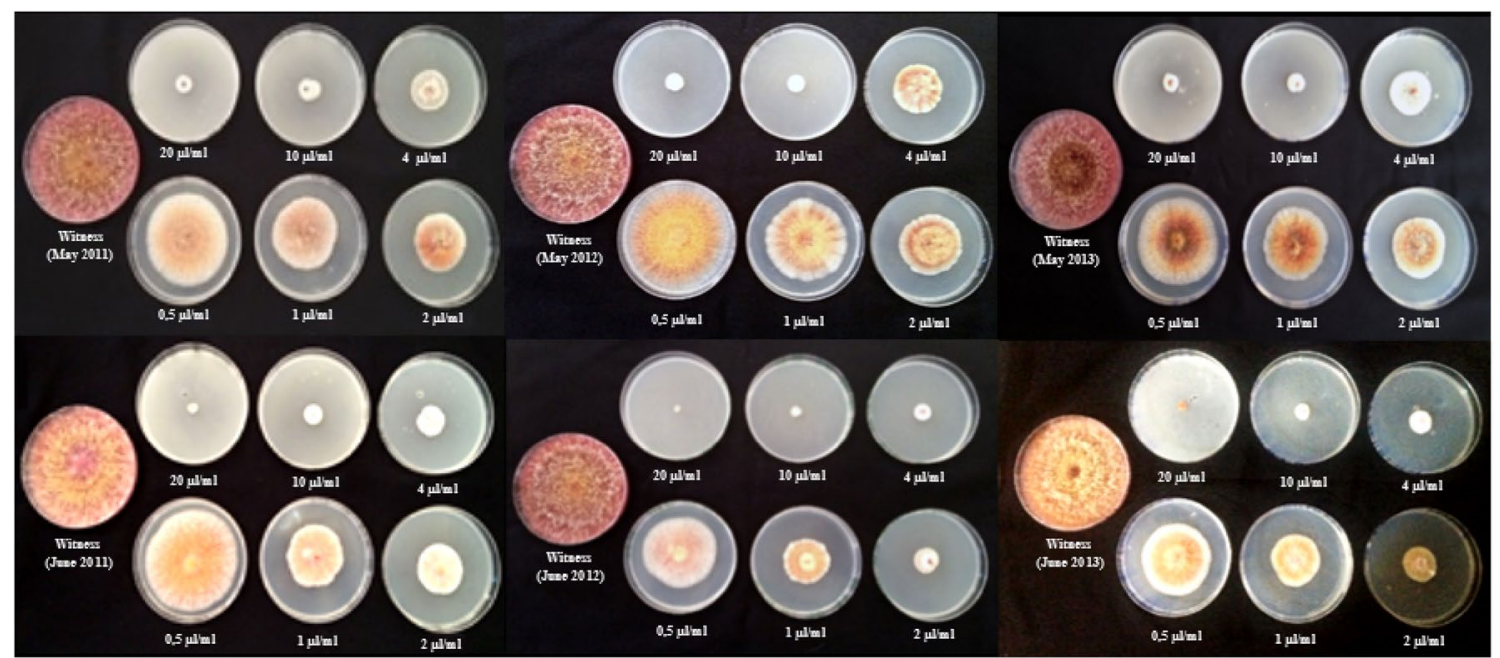

Fig. 2 Examples of the effect of Rhanterium adpressum essential oils from different plant samples on the growth of Fusarium culmorum (T5 strain)

the results of Singh et al. (2005), with the essential oils of Foeniculum vulgare, revealed that $F$. graminearum was very sensitive to the concentrations of 4 and $6 \mu \mathrm{L} / \mathrm{mL}$.

The two strains of $F$. culmorum also exhibited a high sensitivity towards the flowers extract starting from the concentration of $4 \mu \mathrm{L} / \mathrm{mL}$. In previous studies, Terzi et al. (2007) also observed a high inhibition level at the concentration of $5 \mu \mathrm{L} / \mathrm{mL}$ with tea tree essential oil, terpinen-4-ol, 1.8-cineole and $\gamma$-terpinen. On the other hand, at the concentration of $2 \mu \mathrm{L} / \mathrm{mL}$, the essential oil of Cinnamomum zeylanicum exhibited an important inhibition of the growth of F. culmorum (Sumalan et al. 2013). Kordali et al. (2009) reported low susceptibility of $F$. graminearum and $F$. culmorum towards essential oils of Achillea gypsicola and Achillea biebersteinii, despite the richness of these oils in oxygenated monoterpenes (94.42 and $83.98 \%$ ).

\section{Antifungal activity}

\section{Solid medium culture}

The analysis of the antifungal activity of the extracts on solid medium revealed a variability between the effect of the EOs of the leaves and those of the flowers (Fig. 4). The concentration of $20 \mu \mathrm{L} / \mathrm{mL}$ inhibited completely fungal growth for both extracts, if it exceeds the MIC (Table 2). However, the significant difference $(P \leq 0.05)$ between the two EOs started from the concentration of $0.5-10 \mu \mathrm{L} / \mathrm{mL}$. The concentration of $10 \mu \mathrm{L} / \mathrm{mL}$ of 

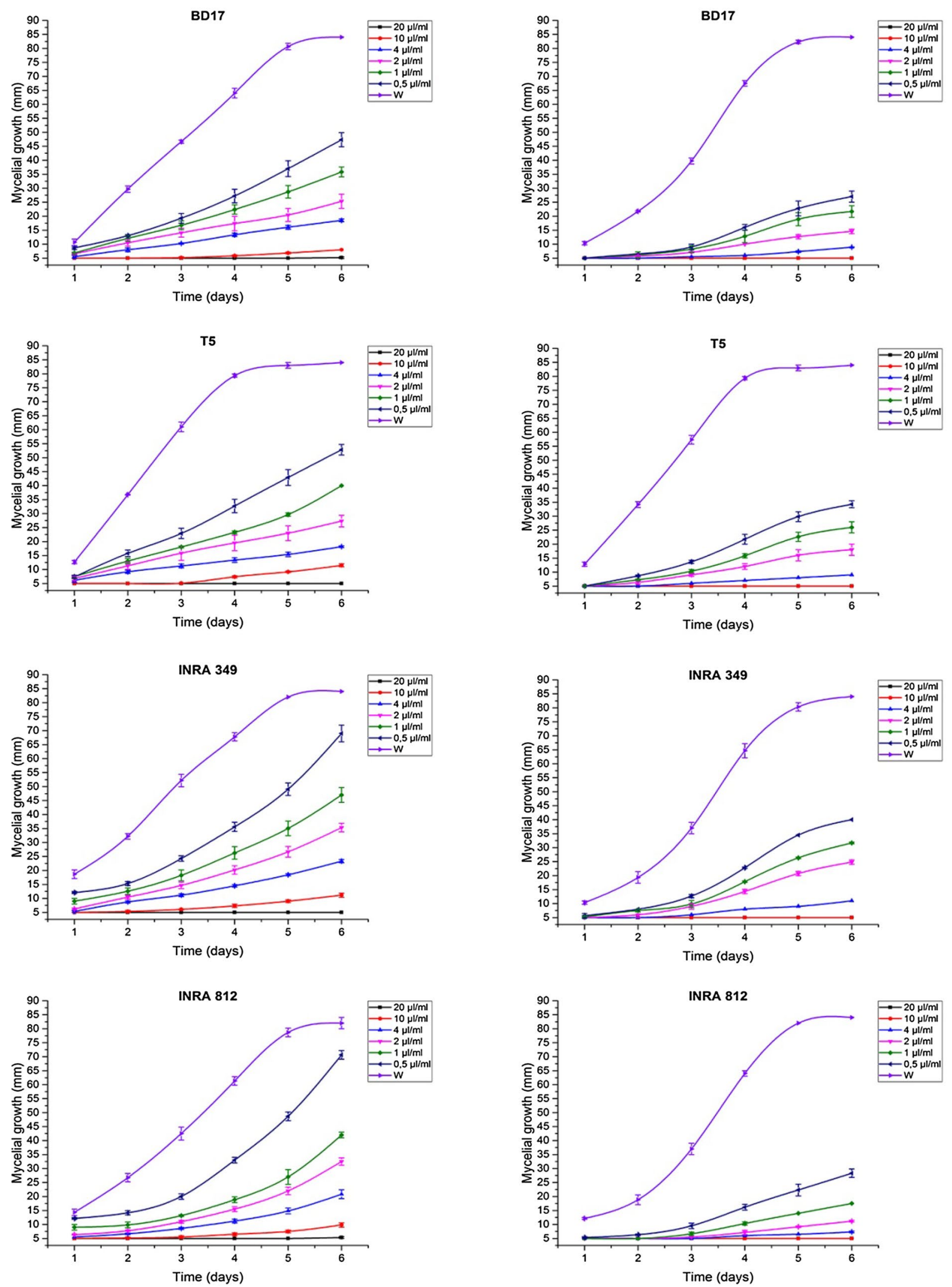

Fig. 3 The mycelial growth kinetics of the four fungal strains in the presence of different concentrations of the two extracts (leaves, on the left, and flowers, on the right) 

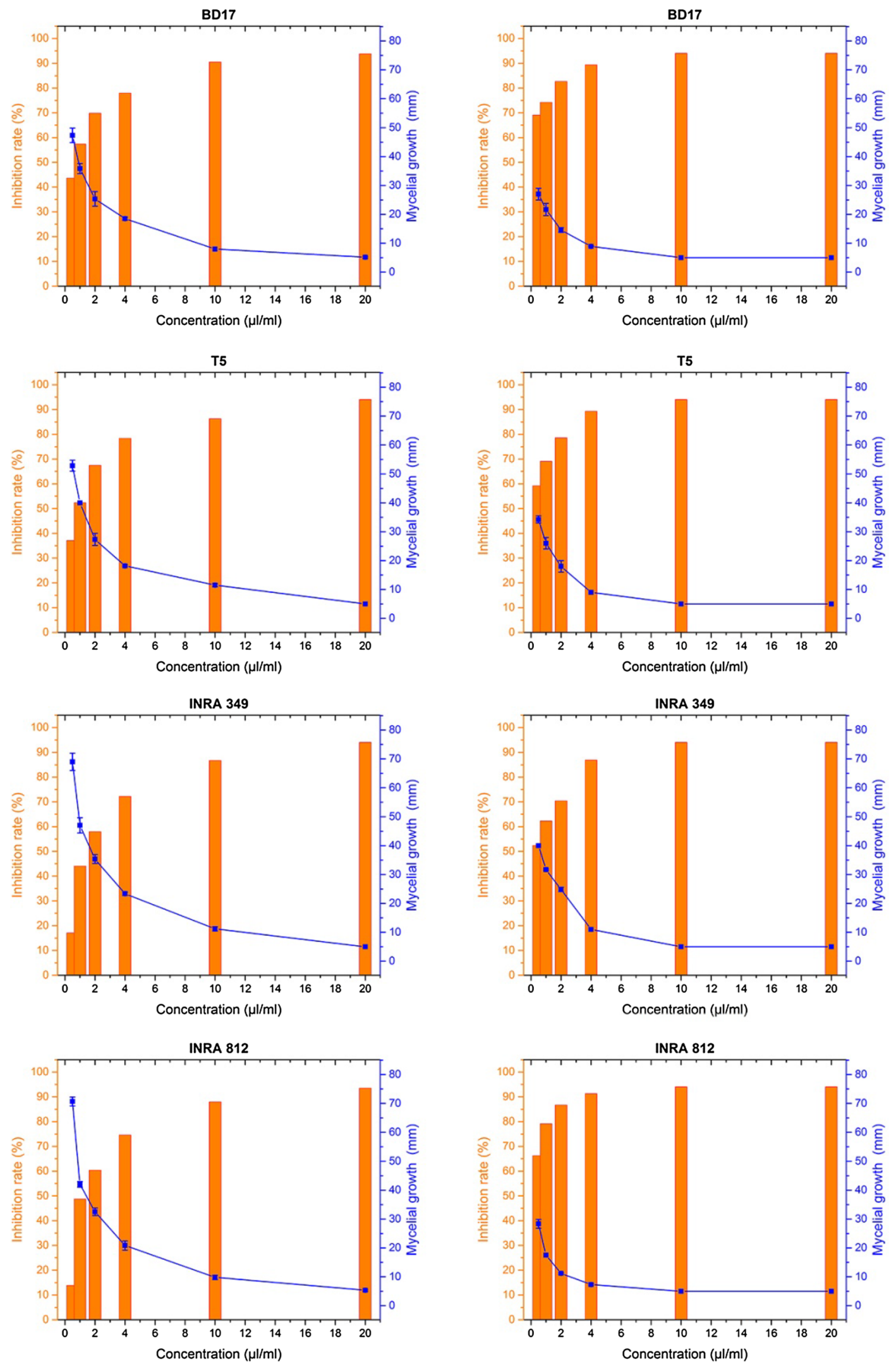

Fig. 4 The antifungal activity on solid medium in the presence of different concentrations of essential oils (leaves, on the left, and flowers, on the right) 
Table 2 The IC50 and MIC values in the presence of different concentrations of the two extracts for the strains of F. culmorum and $F$. graminearum

\begin{tabular}{|c|c|c|c|c|}
\hline & \multicolumn{2}{|l|}{ Leaves } & \multicolumn{2}{|l|}{ Flowers } \\
\hline & $\begin{array}{l}\mathrm{IC50}(\mu \mathrm{L} / \\
\mathrm{mL})\end{array}$ & $\begin{array}{l}\mathrm{MIC}(\mu \mathrm{L} / \\
\mathrm{mL})\end{array}$ & $\begin{array}{l}\mathrm{IC} 50(\mu \mathrm{L} / \\
\mathrm{mL})\end{array}$ & $\begin{array}{l}\mathrm{MIC}(\mu \mathrm{L} / \\
\mathrm{mL})\end{array}$ \\
\hline \multicolumn{5}{|c|}{ Solid culture medium } \\
\hline BD17 & 0.70 & 12.81 & 0.27 & 9.30 \\
\hline T5 & 0.90 & 13.41 & 0.32 & 6.71 \\
\hline INRA 349 & 1.54 & 12.73 & 0.49 & 9.17 \\
\hline INRA 812 & 1.42 & 10.41 & 0.28 & 5.23 \\
\hline \multicolumn{5}{|c|}{ Liquid culture medium } \\
\hline BD17 & 0.27 & 7.79 & 0.23 & 10.37 \\
\hline T5 & 0.24 & 6.69 & 0.20 & 8.84 \\
\hline INRA 349 & 0.26 & 8.05 & 0.24 & 5.85 \\
\hline INRA 812 & 0.37 & 10.40 & 0.22 & 5.90 \\
\hline
\end{tabular}

flowers extract presented the same effect as the concentration $20 \mu \mathrm{L} / \mathrm{mL}$, against all strains, regarding the inhibition rate $(94.04 \%)$. This was not the case with leaves extract, whose inhibition rate was less important than the previous one, and varied between strains. The effect of concentrations $0.5,1,2$ and $4 \mu \mathrm{L} / \mathrm{mL}$ differed significantly between the two extracts. As in the case of flowers extract, the lowest concentration $(0.5 \mu \mathrm{L} / \mathrm{mL})$ generated high levels of inhibition, varying between 52 and $67 \%$, for all strains. However, the inhibition levels of the same concentration for leaves extract did not exceed $50 \%$ (13-47\%).

\section{Liquid culture medium}

The antifungal activity in liquid medium also allowed to note the variability of the inhibitory effect of the extracts (Fig. 5). The strains were more sensitive to the EO of flowers than the EO of leaves. The lowest concentration of the EO derived from flowers $(0.25 \mu \mathrm{L} / \mathrm{mL})$ was capable of inhibiting more than $70 \%$ of the fungal growth. However, the effect of this concentration was about half as much effective as the leaves essential oil. The concentration of $10 \mu \mathrm{L} / \mathrm{mL}$ for all extracts was found sufficient to inhibit completely the growth of the tested strains.

In both culture media, the T5 and INRA 812 strains showed great sensitivity towards the essential oil of flowers (inhibition rate $>60 \%$ in solid medium, $>70 \%$ in liquid medium from lower concentration).

The variability of antifungal potency of EOs on solid and liquid medium, and their effects on mycelial growth, depended on the used concentrations, and on the variation in the chemical composition of the tested extracts.

\section{IC50 and MIC of the extracts}

The susceptibility of the strains INRA 349 and 812 of $F$. graminearum to the extract of flowers is also visible by the calculation of IC50 and MIC (Table 2). The values of these two parameters are significantly different $(P \leq 0.05)$, between extracts of leaves and flowers on solid medium.

The IC50 and MIC presented interesting values in liquid medium with the extract of flowers, but not with a significant difference compared to those of the extract of leaves. According to Dobre and Niculita (2012), F. culmorum and $F$. graminearum were highly sensitive to essential oils of clove, white thyme and oregano at the concentrations of 1 and $1.5 \mu \mathrm{L} / \mathrm{mL}$ PCMs. However, several studies discussed the ineffectiveness of fungicides in controlling the production of mycotoxins, where they are considered sometimes as additional stressors that rather stimulate the production of mycotoxins (Magan et al. 2002; D'mello et al. 1998; Milus and Parsons 1994).

\section{Effect of essential oils on TCTBs trichothecenes production}

The TCTBs trichothecenes are considered as major determinants in the aggressiveness of $F$. culmorum and $F$. graminearum (Wagacha and Muthomi 2007; Muthomi et al. 2000; Eudes et al. 2001). According to their production, the strains of $F$. culmorum and $F$. graminearum were divided into two chemotypes: the NIV chemotype, which includes isolates producing nivalenol and fusarenone $\mathrm{X}$, and DON chemotype, including isolates producing DON and acetyldeoxynivalenol (Wagacha and Muthomi 2007; Bakan et al. 2001). Bakan et al. (2001) have found that total trichothecenes range from 0.052 to $68.1 \mathrm{mg} / \mathrm{kg}$ in sixty strains of F. culmorum. Specimens of Polish wheat ears infected with $F$. culmorum and $F$. graminearum were contaminated with DON (100\%) and 3-ADON (80\%) at very high concentrations (30.4 and $29.54 \mathrm{mg} / \mathrm{kg}$, respectively (Visconti et al. 1986; Bottalico and Perrone 2002). However, 140 specimens of Bulgarian wheat ears, infected with $F$. graminearum 3-ADON and 15-ADON, contaminated 2.1 and $0.7 \%$ of the total with concentrations in excess of $0.1 \mathrm{mg} / \mathrm{kg}$ (Bottalico and Perrone 2002; Vrabcheva et al. 1996). Another study conducted by Touati-Hattab et al. (2016), on Algerian populations of Oued Smar and Rouiba, revealed a correlation between the level of $F$. culmorum invasion and the amount of accumulated TCTB toxins. These authors recorded a production of DON varying between 89 and $340.5 \mu \mathrm{g} / \mathrm{g}$ and 3-ADON between 52.6 and $284.2 \mu \mathrm{g} / \mathrm{g}$.

In our study, the inhibition of the production of the mycotoxins was analyzed in the presence of $0.25 \mu \mathrm{L} / \mathrm{mL}$ of each of our extracts (Fig. 6), where it was the average 

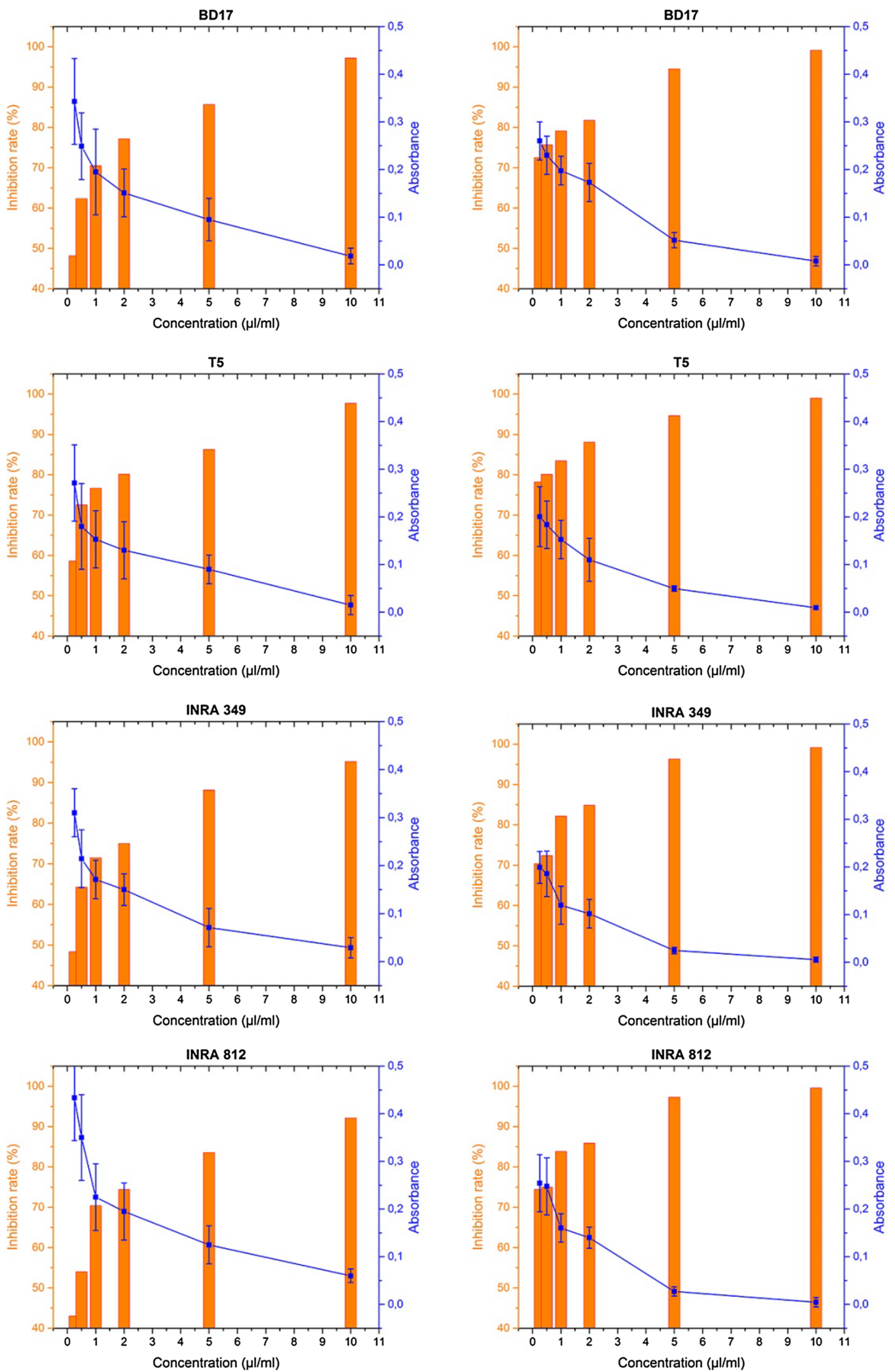

Fig. 5 Antifungal activity in liquid medium in the presence of different concentrations of the two extracts (leaves, on the left, and flowers, on the right) 

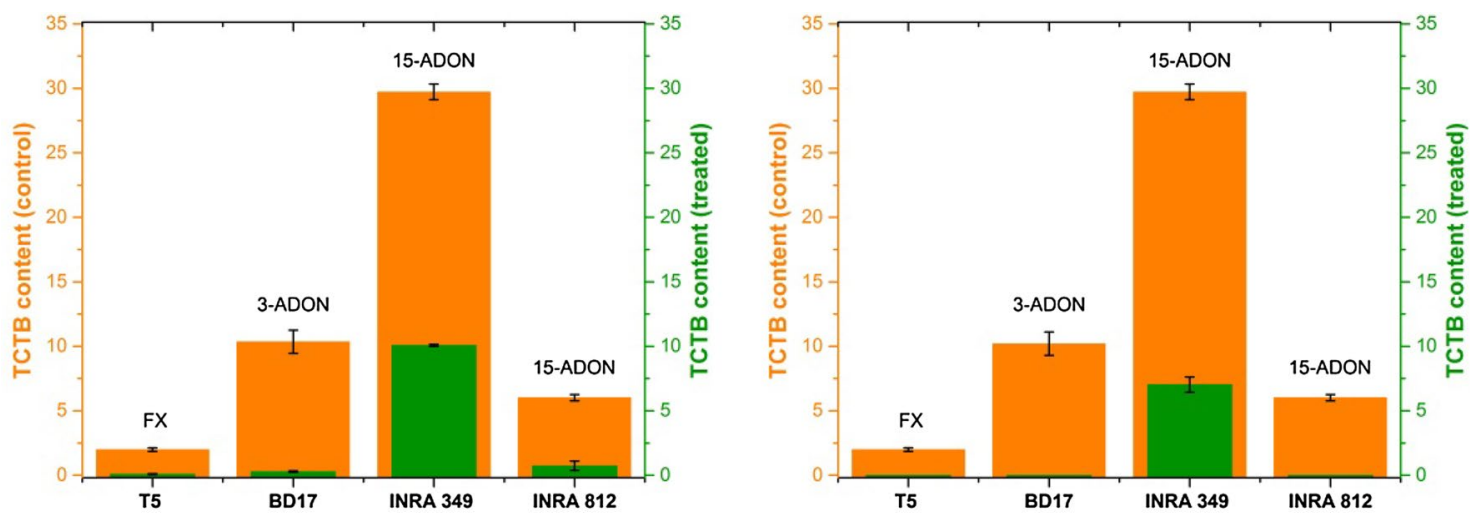

Fig. 6 The production of TCTBs in $\mu \mathrm{g} / \mathrm{mg}$ of mycelium in the absence (control) and in the presence (treated) of $0.25 \mu \mathrm{L} / \mathrm{mL}$ of the EOs of leaves and flowers

concentration of the means, deduced from the results of the inhibition in liquid medium between the two extracts. In the case of leaves extract, production of mycotoxins was more sensitive to the presence of essential oil in F. culmorum strains, where the rate of change between control and post-treatment is between 95-97\% inhibition for FX and 3-ADON. The same result has been noticed for the strains of $F$. graminearum (INRA 812), with a small resistance noticed in INRA 349 , whose inhibition was only $66 \%$. On the other hand, the inhibition of the production of mycotoxins FX, 3-ADON and 15-ADON with the flowers extract was total (100\%) in T5, BD17 and INRA 812 . However, 15 -ADON of INRA 349 showed a low resistance with $76 \%$ inhibition.

\section{Conclusion}

In the present study, the variation of the composition of the essential oils of leaves and flowers of Rhanterium adpressum was noticed, as it was shown in the results of the composition. This variability could have been influenced by, among other elements, the edaphoclimatic factors (drought and rainfall). This difference has also been shown to be important in the antifungal activity against the four studied mycotoxigenic strains of the genus Fusarium. In addition, the activity of the flowers essential oil is evident in the results of the tests on solid and liquid media according to its very interesting concentrations of IC50 and MIC. The two extracts exhibited a remarkable inhibition on the production of mycotoxins, where a $100 \%$ inhibition was recorded for the flowers extract on the three strains: $F$. culmorum T5, BD17 and $F$. graminearum INRA 812. In conclusion, the results of the antifungal power of the essential oils of Rhanterium adpressum and their inhibitory effect on the production of mycotoxins are very interesting. Other complementary work must be carried out on the different chemotypes characterizing the populations of this plant. In addition, the inhibitory compounds should be characterized, and their action levels localized, thus mechanisms of action for these essential oils could be proposed.

Acknowledgements The authors would like to thank Touati Hattab S., Fleurat-Lessard, F. and all the members of the research team of MycSA unit, UR1264, National Institute of Agronomic Research, INRA, Bordeaux, France for their assistance in the realization of this study.

\section{References}

Adams RP (2007) Identification of essential oil components by gas chromatography/mass spectrometry, 4th edn. Allured Publ. Corp, Carol Stream

Amvam Zollo PH, Biyiti L, Tchoumbougnang F, Menut C, Lamaty G, Bouchet P (1998) Aromatic plants of tropical Central Africa. Part XXXII. Chemical composition and antifungal activity of thirteen essential oils from aromatic plants of cameroon. Flavour Fragr J 13:107-114

Bajpai VK, Shukla S, Sharma A (2013) Essential oils as antimicrobial agents. In: Rramawat KG, Merillon JM (eds) Natural products. Springer, Berlin, Heidelberg, p 3975-3988

Bakan B, Pinson L, Cahagnier B, Melcion D et al (2001) Toxigenic potential of Fusarium culmorum strains isolated from French wheat. Food Addit Contam 18(11):998-1003

Benzo M, Gilardoni G, Gandini C et al (2007) Determination of the threshold odor concentration of main odorants in essential oils using gas chromatography-olfactometry incremental dilution technique. J Chromatogr A 1150(1-2):131-135

Böhme K, Barros-Velázquez J, Calo-Mata P, Aubourg SP (2014) Antibacterial, antiviral and antifungal activity of essential oils: mechanisms and applications. In: Villa T, Veiga-Crespo P (eds) Antimicrobial compounds. Springer, Berlin, Heidelberg

Bottalico A, Perrone G (2002) Toxigenic Fusarium species and mycotoxins associated with head blight in small-grain cereals in Europe. Eur J Plant Pathol 108(7):611-624

Bouaziz M, Dhouib A, Loukil S et al (2009) Polyphenols content antioxidant and antimicrobial activities of extracts of some wild plants collected from the south of Tunisia. Afr J Biotechnol 8(24):7017-7110 
Bouheroum M, Benayache SF, Benayache L, Zaiter J, Barrera M, Francisco L (2007) Terpenoids and triynepoxide from the aerial part of Rhantherium adpressum. Chem Nat Compd 43:110-111

Boussoussa H, Hamia C, Djeridande A et al (2014) Effect of different solvent polarity on extraction of phenolic compounds from Algerian Rhanterium adpressum flowers and their antimicrobial and antioxidant activities. Curr Chem Biol 8:1-7

Chehma A (2006) Catalogue des plantes spontanées du Sahara septentrional Algérien. Laboratoire de "Protection des écosystèmes en zones arides et semi aride ». Edition Dar El Houda. ISBN:9947-0-1312-X

Collin GJ, Lord D, Allaire J, Gagnon D (1989) Huiles essentielles et extraits 'micro-ondes'. Parfums Cosmétiques Arômes 97:105-112

D'mello JF, Macdonald AM, Postel D et al (1998) Pesticide use and mycotoxin production in Fusarium and Aspergillus phytopathogens. Eur J Plant Pathol 104(8):741-751

Dobre AA, Niculita P (2012) Preliminary research to develop active packaging for bakery products using essential oils. Sci Bull Ser F Biotechnol XVI:139-144

Dorman HJD, Deans SG (2000) Antimicrobial agents from plants: antibacterial activity of plant volatile oils. J Appl Microbiol 88(2):308-316

El Ajjouri M, Satrani B, Ghanmi M et al (2008) Activité antifongique des huiles essentielles de Thymus bleicherianus Pomel et Thymus capitatus (L.) Hoffm. \& Link contre les champignons de pourriture du bois d'œuvre. Biotechnol Agron Soc Environ 12:345-351

El Houiti F, Tahri D, Seba M et al (2016) Inhibition of Fusarium oxysporum f. sp. albedinis by essential oils of flowers and stems of Rhanterium adpressum. PhOL PharmacologyOnLine 3(22):141-150

Eudes F, Comeau A, Rioux S, Collin J (2001) Impact of trichothecenes on Fusarium head blight [Fusarium graminearum] development in spring wheat (Triticum aestivum). Can J Plant Pathol 23(3):318-322

Fleurat-Lessard F, Bergougnoux M, Debourdeau G, Barreau C (2015) In vitro large screening of bioactive compounds of botanical origin for antifungal activity against two mycotoxigenic fungi of wheat: Aspergillus westerdijkiae and Fusarium graminearum. In: Arthur FH, Kengkanpanich R, Chayaprasert W, Suthisut D (Eds.) Actes de la 11e Conférence internationale de travail sur la protection stockée produit 24-28 November 2014 Chiang Mai, p $1045-1060$

Hamia C, Gourine N, Boussoussa H et al (2013) Chemical composition and antioxidant activity of the essential oil and fatty acids of the flowers of Rhanterium adpressum. Nat Prod Commun $8(8): 1171-1173$

Holopainen JK, Himanen SJ, Yuan JS, Chen F, Stewart, CN Jr (2013) Ecological functions of terpenoids and climate changes. In: Ramawat KG, Merillon JM (eds) Handbook of natural products. Springer, p 2913-2940

Kala A, Gherraf N, Belkacemi D et al (2009) Composition of the essential oil of Rhanterium adpressum Coss. and Durieu from Algeria. Arch Appl Sci Res 1:115-118

Kim JM, Marshall MR, Cornell JA et al (1995) Antibacterial activity of carvacrol, citral, and geraniol against Salmonella typhimurium in culture medium and on fish cubes. J Food Sci 60(6):1364-1368
Kordali S, Cakir A, Akcin TA et al (2009) Antifungal and herbicidal properties of essential oils and n-hexane extracts of Achillea gypsicola Hub-Mor. and Achillea biebersteinii Afan. (Asteraceae). Ind Crops Prod 29(2):562-570

Magan N, Hope R, Colleate A, Baxter ES (2002) Relationship between growth and mycotoxin production by Fusarium species, biocides and environment. Eur J Plant Pathol 108:685-690

Merhej J, Richard-Forget F, Barreau C (2011) The pH regulatory factor Pac1 regulates Tri gene expression and trichothecene production in Fusarium graminearum. Fungal Genet Biol 48:275-284

Milus EA, Parsons CE (1994) Evaluation of foliar fungicides for controlling Fusarium head blight of wheat. Plant Dis 78:697-699

Muthomi JW, Schütze A, Dehne HW et al (2000) Characterization of Fusarium culmorum isolates by mycotoxin production and aggressiveness to winter wheat. J Plant Dis Prot 107:113-123

Özek G, Özek T, Işcan G et al (2008) Composition and antimicrobial activity of the oils of Ferula szowitsiana DC. from Turkey. J Essent Oil Res 20(2):186-190

Pirgozliev VR, Birch CL, Rose CP et al (2003) Chemical composition and the nutritive quality of different wheat cultivars for broiler chickens. Br Poult Sci 44:464-475

Remmal A, T-elaraki A, Bouchikhi T et al (1993) Improved method for the determination of antimicrobial activity of essential oils in Agar medium. Essent Oil Res 5:179-184

Satrani B, farah A, fechtal M et al (2001) Composition chimique et activité antimicrobienne des huiles essentielles de Satureja calamintha et Saturija alpina du Maroc. Ann Fals Exp Chim 956:241-250

Singh G, Maurya S, De Lampasona MP, Catalan C (2005) Studies on essential oils, Part 44: chemical, antifungal, antioxidant activity of Foeniculum vulgare volatile oil and its oleoresins. Food Control 20(1):1-6

Sumalan RM, Alexa E, Poiana MA (2013) Assessment of inhibitory potential of essential oils on natural mycoflora and Fusarium mycotoxins production in wheat. Chem Cent J 7(1):1

Terzi V, Morcia C, Faccioli P et al (2007) In vitro antifungal activity of the tea tree (Melaleuca alternifolia) essential oil and its major components against plant pathogens. Lett Appl Microbiol 44(6):613-618

Touati-Hattab S, Barreau C, Verdal-Bonnin MN et al (2016) Pathogenicity and trichothecenes production of Fusarium culmorum strains causing head blight on wheat and evaluation of resistance of the varieties cultivated in Algeria. J Plant Pathol 145(4):797-814

Velluti A, Sanchis V, Ramos AJ et al (2004) Impact of essential oils on growth rate, zearalenone and deoxynivalenol production by Fusarium graminearum under different temperature and water activity conditions in maize grain. J Appl Microbiol 96(4):716-724

Visconti A, Chelkowski J, Bottalico A (1986) Deoxynivalenol and 3-acetyldeoxynivalenol-mycotoxins associated with wheat head fusariosis in Poland. Mycotoxin Res 2(2):59-64

Vrabcheva T, Geßler R, Usleber E, Märtlbauer E (1996) First survey on the natural occurrence of Fusarium mycotoxins in Bulgarian wheat. Mycopathologia 136(1):47-52

Wagacha JM, Muthomi JW (2007) Fusarium culmorum: infection process, mechanisms of mycotoxin production and their role in pathogenesis in wheat. Crop Prot 26(7):877-885 